\title{
Too Cool for School? The Relationship between Coolness and Academic Reputation in Early Adolescence
}

\author{
Rhonda S. Jamison, ${ }^{1}$ Travis Wilson ${ }^{2}$ and Allison Ryan ${ }^{3}$ \\ ${ }^{1}$ University of Maine at Farmington \\ ${ }^{2}$ Oberlin College \\ ${ }^{3}$ University of Michigan
}

\begin{abstract}
The relationship between peer-nominated coolness and academic reputation was examined at two time points spanning the first year of middle school $(\mathbb{N}=807 ; 52$ percent female; 52 percent African-American; 48 percent European American). Students predominantly nominated peers who were from their same gender and ethnic group as being cool. Associations between coolness and academic reputation differed across subgroups, were contingent upon level of disruptive behavior, and changed over time from fall to spring of the academic year. In the fall, patterns differed by gender, not by ethnicity. For both white and African-American boys, hierarchical regressions evidenced a null association between coolness and academic reputation; for both white and African-American girls, this association was positive. In the spring, findings for white girls were similar to findings from the fall. For the three remaining groups-white boys and African-American boys and girls - conditions worsened over time, albeit in slightly dissimilar ways. For white boys, fall coolness did not predict significant declines in academic reputation over time; nonetheless, as a group, the coolnessacademic reputation was negative by the end of the year. For African-American boys and girls, fall coolness significantly predicted declines in academic reputation from fall to spring, although the concurrent coolness-academic reputation association was not significantly negative for either group in the spring.
\end{abstract}

Keywords: adolescence; education; popularity; peers/peer relations

\section{Introduction}

What does it mean to be cool at school? Coolness indicates the embodiment of some combination of attributes that wins approval or earns the attention of others. Scholars have long investigated the implications of social status at school for students' social and academic development. For several decades the focus was on students who were at

Correspondence should be addressed to Rhonda S. Jamison, Department of Psychology, University of Maine at Farmington, 234 Main Street, Farmington, ME 04938, USA. Email: Rhonda.Jamison@ Maine.edu 
the bottom rungs of the social ladder - the rejected or unpopular students (e.g., Asher $\&$ Coie, 1990). Not surprisingly, such students were at risk for poor developmental outcomes (Parker \& Asher, 1987; Wentzel \& Asher, 1995). More recently, the students at the top of the social ladder are getting increased attention from researchers. High social status, which was once thought to be positive and adaptive, presents mixed findings in the literature (for a review, see Cillessen \& van den Berg, 2012). One drawback for high social status youth may be disinvestment in school, especially during early adolescence, a time when motivation and achievement decline (Eccles et al., 1993). How might 'being cool' be related to students' investment in schoolwork? Is coolness a risk factor for students' investment in school, or might it be associated with positive investment outcomes? We address these questions by examining the relationship between coolness and academic reputation in the fall and spring of students' first year in middle school as well as the developmental implications of coolness in the fall for changes in academic reputation across the school year. In addition, we investigate whether there are differences in the relations between coolness and academic reputation by gender and ethnic groups.

The present study makes a unique contribution to the field, studying the intersection of social and academic processes by examining peer nominations of coolness and academic effort. Examination of peer nominations allows us to understand how having a reputation of coolness is related to a reputation of academic effort, through the eyes of the early adolescents themselves. This differs from academic performance, as it is the peers' perceptions that matter and not the student's actual grades. Examining academic reputation provides a window into the peer culture surrounding social status and academic engagement in early adolescence and allows us the distinctive ability to analyze how students view one another.

We use a coolness measure as an indicator of high social status. Student nominations of who is cool have been used to tap into high social status because 'coolness is a developmentally appropriate index of status, geared toward and created by youth' (Rodkin, Farmer, Pearl, \& Van Acker, 2006). In fact, popular fourth-, fifth-, and sixth-grade students are frequently nominated as cool (Rodkin, Farmer, Pearl, \& Van Acker, 2000). When asked to list descriptors of what it means to be popular, middle school students listed cool more frequently than any other descriptor (Closson, 2009). But the word 'popular' had other meanings to students such as attractive, athletic, or mean. We use 'coolness' as a measure of high social status in order to avoid the alternate connotations that are elicited with the word 'popular'. We do not make the assumption that popularity and coolness are identical, although we do expect them to operate similarly. Given the highly related nature of cool and popular, and the lack of literature related to a measure of coolness, we draw on the larger literature of popular youth (e.g., Cillessen \& van den Berg, 2012) to build our rationale in regard to how 'being cool' relates to academic reputation.

\section{Outcomes Associated with Popularity and Disruptive Behavior}

There has been increasing interest in the last decade in understanding the correlates and consequences of being perceived as popular. At first, attention was placed on social adjustment outcomes such as social behaviors (Cillessen \& Rose, 2005) and risky behaviors such as alcohol and drug use (Mayeux, Sandstrom, \& Cillessen, 2008). Limited research linking perceived popularity and academic outcomes exists, but suggests a relationship between the two. For example, adolescents described 
hypothetical popular peers as more academically successful and smarter than hypothetical unpopular peers (LaFontana \& Cillessen, 2002). But when presented with hypothetical dilemmas, adolescents prioritized popularity over academic achievement or following rules in school (LaFontana \& Cillessen, 2010). We hypothesize that there will be a positive relation between coolness and academic reputation at the beginning of the school year but that this relation may change across the school year as peers become more influential.

An additional consideration is that perceived popular students often present a mix of prosocial and antisocial behaviors (Rodkin et al., 2000; Sandstrom \& Cillessen, 2006); thus, it is important to include disruptive behaviors when examining the developmental trajectories of popular students. In addition to having varying adjustment trajectories, popular-prosocial and popular-antisocial students are viewed differently by their peers. Among elementary school students, popular-prosocial boys tended to be nominated by peers as being good students, leaders, and cooperative, whereas popular-antisocial boys tended to be nominated by peers as starting fights, being disruptive, and getting into trouble (Rodkin et al., 2000). Also, among sixth graders, there was a relationship between being nominated by peers as cool and being nominated by peers as aggressive (Bellmore, Villarreal, \& Ho, 2011; Hoff, Reese-Weber, Schneider, \& Stagg, 2009). This interaction of popularity and behavior leads to varying academic outcomes. Among late elementary school students, popularity in aggressive children, but not in non-aggressive children, is related to a trajectory of declining academic performance and increasing school avoidance (Troop-Gordon, Visconti, \& Kuntz, 2011). The interaction between popularity and aggressive behavior predicts academic functioning, with those who are aggressive and low in popularity reporting the lowest academic functioning (Cillessen \& Mayeux, 2007). In a high school sample, popularity was linked to negative academic outcomes only for students who had increases in aggressive behavior (Schwartz, Gorman, Nakamoto, \& McKay, 2006). Thus, it appears that a combination of popularity and antisocial behavior - not simply popularity in and of itselfmay hinder academic performance. The present study examines the intersection between perceived coolness and disruptive behavior in predicting academic reputation among students. We hypothesize that students who are high in coolness and disruptive behavior will be viewed as less academically effortful.

\section{Middle School}

Despite increasing interest in the intersection of academic and social development, a gap exists in the current knowledge of the relation between social status and academic outcomes; most of the research has focused on elementary or high school students, leaving relations in middle school students largely unexamined. In American education, many students transition out of smaller, more intimate elementary schools into larger middle schools. They transition from having one primary teacher for the entire day to having several subject-specific teachers throughout the day. They also move from being embedded in a classroom with 20-30 other students for the entire day to switching classes and classmates throughout the day. These adjustments, along with the other physical, cognitive, and social changes of early adolescence, make the transition to middle school a challenging time for some adolescents. Studies evidence declines in motivation, academic engagement, and achievement during this time (Eccles, 2004; Eccles et al., 1993). This is troubling considering that disengagement and maladjustment during early adolescence can negatively impact long-term academic trajectories. 
In early adolescence, children begin to spend more time with friends (Larson et al., 2002) and place more importance on the maintenance of friendships (Berndt \& Savin-Williams, 1993). Adolescents focus on popularity more than younger or older students and, beginning in middle school, they increasingly prioritize popularity over academic achievement and adherence to rules for behavior (LaFontana \& Cillessen, 2010). Middle school is also a time when students' definition of social success changes. In elementary school, students report that socially successful children are sincere and responsible students. But in the first year of middle school, students' reports of socially successful peers are less likely to indicate sincerity and responsibility and more likely to indicate dominance and disingenuity (Kiefer \& Ryan, 2011).

Moffitt (1993) presents a theoretical framework that partly explains this shift. The 'maturity gap' theory suggests that in modern society, adolescents are trapped in a challenging social space where they want to be seen and treated like autonomous adults, but they are still considered children in many respects. To deal with the gap between pubertal maturity and societal maturity, some adolescents assert their autonomy through non-compliance and delinquency. Many adolescents are attracted to such 'non-normative' peers and mimic their behaviors, thereby creating a shift in norms. They begin to show positive regard for dominant, aggressive peers and less positive regard for compliant peers (Bukowski, Sippola, \& Newcomb, 2000). This shift in norms is also evident in behaviors related to academics. Beginning in middle school, students think that peers who exhibit low effort are more popular than effortful students. When rating hypothetical peers, fourth- and sixth-grade students rated effortful students as being more popular with their peers (Juvonen \& Murdock, 1995). In eighth grade, students continue to rate hypothetical peers who portray effort to teachers as being popular but are less likely to rate peers who portray effort to students as popular (Juvonen \& Murdock, 1995). Thus, we expect that there may be a positive association between coolness and academic reputation at the beginning of middle school that may change to a more negative relationship over time. The first year in middle school is an ideal time to examine this relationship because peers are becoming more salient just as students' motivation and achievement are declining.

\section{Gender and Ethnicity}

Peer status systems, classroom behavior, and academic engagement interact with gender and ethnicity in complex ways. Gender is a strong factor in peer relations as early as preschool and continues to be a source of social segregation through adolescence (Maccoby, 1996; Rose \& Smith, 2009). Children also evidence social segregation by ethnicity during elementary school and this trend strengthens throughout middle school (Graham, Taylor, \& Ho, 2009). Spending so much of their time in friendships and peer groups segregated by sex and ethnicity fosters gender and ethnic differences in patterns of socialization at school.

Gender differences predominate in styles of peer interaction in ways that may have implications for gender differences in academic functioning. Most notably, girls tend to value close, dyadic interpersonal relationships, whereas boys tend to value connection to groups (Baumeister \& Sommer, 1997). Correspondingly, boys more frequently engage in competitive group activities (Mathur \& Berndt, 2006) and exhibit higher levels of overt aggression (Archer, 2004), whereas girls spend more time talking with peers (Blatchford, Baines, \& Pellegrini, 2003) and evidence greater levels of personal disclosure, particularly after entrance to middle school (Rose \& Rudolph, 2006). 
Regarding academic engagement, middle school girls demonstrate more cooperative academic behaviors in the classroom (Barry \& Wentzel, 2006) and report valuing academic achievement more than boys do, although their expectations for academic success are not higher (Kenney-Benson, Pomerantz, Ryan, \& Patrick, 2006). Gender differences in academic-related behavior and academic motivation notwithstanding, no consistent gender difference in associations between popularity and academic achievement has been documented (see Rose, Glick, \& Smith, 2011), suggesting that the influence of peer status systems on academic achievement operates similarly for adolescent boys and girls.

Ethnic differences in young adolescents' schooling experiences emerge during elementary school and become more salient throughout middle school (Wigfield, Eccles, Schiefele, Roeser, \& Davis-Kean, 2006). African-American students, in particular, face unique challenges during middle school that undermine academic engagement; these challenges take form at many levels, from broad structural social inequality to everyday interpersonal interactions (Taylor \& Graham, 2007). AfricanAmerican students often report an awareness of persistent systemic inequalities in American society and a belief that structural inequalities limit their opportunities for social and economic mobility (e.g., Carter, 2006; Mickelson, 1990; O'Connor, 1999; Taylor, Casten, Flickinger, Roberts, \& Fulmore, 1994). At a more proximal level, ethnic minorities are increasingly distressed throughout adolescence by the experiences of discrimination in their everyday social interactions, which induce feelings of alienation from school and declines in academic performance (Fisher, Wallace, \& Fenton, 2000; Wong, Eccles, \& Sameroff, 2003). African-American males are especially vulnerable to these obstacles. Compared with their female counterparts, AfricanAmerican male adolescents consistently experience worse academic outcomes, report having less positive attitudes toward school, obtain lower grades and test scores, and are retained more frequently (Graham, Taylor, \& Hudley, 1998; Jordan \& Cooper, 2003; Taylor \& Graham, 2007).

Despite the challenges to academic success faced by ethnic minority students, there is no documented ethnic difference in associations between popularity and academic achievement. Of the few studies that have directly examined associations between popularity and academic achievement among multiple ethnic groups, no clear distinction between ethnic groups has been found (for a review, see Bellmore, Nishina, \& Graham, 2011). However, some evidence suggests that African-American males may be disproportionately influenced by peers in academically compromising ways. For example, Taylor and Graham (2007) examined the degree to which middle school students admired and respected high- versus low-achieving peers and found striking differences between African-American girls and boys. Whereas seventh-grade AfricanAmerican girls were more likely to nominate high- or average-achieving same-gender classmates as those whom they admired, respected, and wanted to be like, AfricanAmerican boys showed a relative preference for low-achieving same-gender classmates, especially when they perceived greater obstacles to achieving desirable levels of education and job attainment. This study corroborated similar findings from an earlier study, in which the authors concluded that minority boys, more so than other adolescents, contend with multiple psychosocial stressors that undermine the potential for their peer groups to reinforce positive academic engagement (Graham et al., 1998).

In summary, studies of associations between social status and objective indicators of academic performance have evidenced no consistent gender or ethnic differences, although some evidence suggests that African-American males are vulnerable to 
negative influences by peers. That said, adolescents' achievement values are multifaceted and responsive to multiple influences from school settings (Downey \& Ainsworth-Darnell, 2002; Graham et al., 1998; Mickelson, 1990). In addition to examining associations between status among peers and objective indicators of academic performance, as described above, examining whether high-status students also tend to be perceived by their peers as high-achieving bears importance, because students' perceptions of their school's social environment alone can strongly influence their academic motivation (Meece, Anderman, \& Anderman, 2006). By examining the correspondence between a student's academic reputation and her perceived coolness among classmates, the present study addresses this concern. Given that AfricanAmerican students - especially males - are vulnerable to a greater number of obstacles to scholastic success, the implications of these links may be stronger for this group. A positive association between academic reputation and coolness would serve to work against some of the challenges confronting young adolescent students; a negative association would exacerbate them.

\section{Present Study}

The objective of the present study was to examine how coolness is related to academic reputation during the first year of middle school and whether these associations differ based on gender or ethnicity. First, we examined who was nominated as cool by their peers. Consistent with prior research (Graham et al., 1998; Taylor \& Graham, 2007), we hypothesized that students would disproportionately nominate peers who were from the same gender and the same ethnicity as themselves. Next, we examined the concurrent relationship (in fall and spring) between coolness and academic reputation, after controlling for disruptive behavior. We hypothesized that there is a positive relationship between coolness and academic reputation at the beginning of the year, with those students who were viewed as cool having academic reputations of working hard and making good grades. Lastly, we examined the relationship between coolness and academic reputation across the school year, controlling for students' initial levels of academic reputation. We hypothesized that coolness is negatively related to changes in students' academic reputation; that is, students who are perceived to be cool at the beginning of the school year show declines in academic reputation across the school year, paralleling previous findings that deviant and non-compliant behavior have more cachet among young adolescents as they proceed through middle school.

\section{Method}

\section{Schools}

The data were collected as part of the University of Illinois Adolescent Transitions Project, a two-year longitudinal study examining changes in academic and social adjustment across the transition to middle school. Participants were in their first year of middle school (seventh grade, typically at the age of 12-13 years) and attended one of three schools. These schools serve non-metropolitan, small urban communities. The average rate of eligibility for free or reduced-fee lunch was 59 percent.

\section{Participants}

Only African-American and white students were included in the study because the very small numbers of other ethnic groups rendered separate analyses of these students 
untenable. This yielded a sample of 807 students in the fall (52 percent female, 52 percent African-American) and 742 students in the spring (53 percent female, 51 percent African-American). The three schools were chosen in part because of their similarity in racial demographics and their small urban locations. The attrition rate of 8 percent was largely due to mobility of students. We compared the students who participated at both time points to those who dropped out of the study after the first time point on the variables examined in the current study. Students in the longitudinal sample did not differ from the students who dropped out on demographic variables or perceived coolness, but were perceived as less academically engaged $(\Delta m=.08$, $t=-4.4, p<.01)$ and more disruptive $(\Delta m=.82, t=5.25, p<.01)$ at the first time point.

\section{Measures}

Peer Nominations of Cool. Participants were presented with the prompt: 'Think about all the students in the $7^{\text {th }}$ grade. Which students are really cool (just about everyone in school knows this person)?' Participants were allowed to nominate up to three students. Self-nominations were excluded. Nominations were standardized within school and then over the entire sample. Rodkin et al. (2006) found the three-week test-retest stability of this item ranged from $r=.72$ to .93 .

Peer Nominations of Effort and Disruptive Behavior. Participants were presented with the prompt: 'Think about all the students in the $7^{\text {th }}$ grade. Which students ...' Participants were allowed to nominate up to three students for each item. Selfnominations were excluded. Items were standardized within school and then over the entire sample. The nominations for 'work hard and get good grades' and 'goof off and do not get good grades' were combined by subtracting the latter from the former in order to make a measure of academic reputation. The nominations for 'does not follow school rules (and gets into trouble)' and 'follow school rules' were combined by subtracting the latter from the former in order to make a measure of peer-nominated disruptive behavior.

\section{Procedure}

Two weeks prior to each data collection, letters describing the project were given to all students to take home to their parents. If parents did not want their child to participate in the study, they were instructed to have their child return an attached form to the teacher, call the school, or call the researchers at the university telephone number provided on the letter. All teachers were given two copies of the letter for each student, and teachers checked with students that the letters were delivered home. Fewer than 5 percent of the parents declined to have their child participate at either collection.

Surveys were administered to students in their classrooms by two trained research assistants. Instructions and items were read aloud while students read along and responded. Students were told that the purpose of the survey was to find out about students' beliefs and behaviors, that the survey was not a test, that there were no right or wrong answers, and that their survey responses would be kept confidential. In addition, students were told that filling out the survey was voluntary. Research assistants visited the schools twice, once for initial administration and one additional day to administer make-ups for students who were absent. 


\section{Results}

Preliminary Analyses and Analysis Plan

Descriptive information about who students nominate as cool revealed that group members predominantly nominated other in-group members. Specifically, AfricanAmerican boys predominantly nominated African-American boys (68 percent of their nominations), African-American girls nominated African-American girls ( 82 percent), white boys nominated white boys ( 86 percent), and white girls nominated white girls ( 85 percent). In addition, preliminary explorations indicated the presence of significant four-way interactions (gender $\times$ ethnicity $\times \operatorname{cool} \times$ disruptive behavior). Given that the students overwhelmingly nominated within gender and ethnic group and that patterns varied by both gender and ethnicity, we conducted analyses separately for four groups: African-American boys, African-American girls, white boys, and white girls. Similar approaches have been used in prior research to aid clarity of presentation and interpretation (e.g., Graham et al., 1998).

\section{Who Is Nominated as Cool?}

Tables 1 and 2 display cool nominations from the whole sample and for different groups. In the fall, 48 percent of students received at least one cool nomination. In the spring, 43 percent received at least one cool nomination. Nominations across different groups were similar. Of those who received at least one cool nomination, the mean number of nominations was 2.53 for fall and 3.02 for spring.

\section{Correlations among Variables}

Cool status was moderately stable across the school year for all groups (ranging from $r=.61$ to .72 ). Coolness and concurrent disruptive behavior in the fall and the spring,

Table 1. Descriptive Statistics of Peer Nomination Variables in Fall (T1) and Spring (T2) by Group

\begin{tabular}{lcccccc}
\hline Variables & & & White boys & Black boys & White girls & Black girls \\
\hline Coolness & & & & & \\
& & & & & & \\
& & $(S D)$ & $(1.116)$ & $(1.126)$ & $(1.15)$ & $(1.079)$ \\
& $\mathrm{T} 2$ & $M$ & .245 & .248 & .272 & .203 \\
Disruptive behavior & $\mathrm{T} 1$ & $(S D)$ & $(1.207)$ & $(1.155)$ & $(1.28)$ & $(1.073)$ \\
& & $(S D)$ & -.353 & .325 & -.336 & .286 \\
& $\mathrm{~T} 2$ & $M$ & -.282 & .243 & -.347 & .335 \\
& & $(S D)$ & $(1.493)$ & $(1.326)$ & $(1.223)$ & $(1.478)$ \\
Academic effort & $\mathrm{T} 1$ & $M$ & -.008 & -.096 & .111 & .048 \\
& & $(S D)$ & $(.199)$ & $(.206)$ & $(.144)$ & $(.109)$ \\
& $\mathrm{T} 2$ & $M$ & -.016 & -.106 & .146 & .053 \\
& & $(S D)$ & $(.262)$ & $(.274)$ & $(.195)$ & $(.163)$ \\
\hline
\end{tabular}

Note: $M=$ mean; $S D=$ standard deviation. 
Table 2. Percentage of Cool Nominations Received in Fall (T1) and Spring (T2) for Whole Sample and by Group

\begin{tabular}{lccccc}
\hline Fall & Whole sample & White boys & Black boys & White girls & Black girls \\
& $N=807$ & $n=198$ & $n=188$ & $n=188$ & $n=233$ \\
\hline 0 & 52 Percent & 56 Percent & 46 Percent & 57 Percent & 48 Percent \\
1 & 22 & 23 & 23 & 21 & 22 \\
2 & 11 & 5 & 13 & 8 & 16 \\
3 & 6 & 5 & 5 & 7 & 5 \\
4 & 3 & 3 & 3 & 1 & 4 \\
5 & 2 & 3 & 3 & 1 & 1 \\
6 & 1 & 0 & 3 & 2 & 0 \\
7 & $<1$ & $<1$ & $<1$ & 0 & $<1$ \\
$8+$ & 2 & 2 & 2 & 2 & 3 \\
\hline & Whole sample & White boys & Black boys & White girls & Black girls \\
Spring & $N=742$ & $n=182$ & $n=162$ & $n=185$ & $n=213$ \\
\hline 0 & 57 Percent & 64 Percent & 56 Percent & 57 Percent & 54 Percent \\
1 & 20 & 13 & 20 & 23 & 25 \\
2 & 8 & 10 & 9 & 6 & 6 \\
3 & 4 & 4 & 3 & 5 & 4 \\
4 & 2 & $<1$ & 3 & 2 & 3 \\
5 & 2 & 2 & 0 & 3 & 2 \\
6 & 1 & $<1$ & 2 & 1 & 1 \\
7 & $<1$ & $<1$ & 1 & 0 & 1 \\
$8+$ & $<1$ & 5 Percent & 5 & 3 & 3 \\
\hline
\end{tabular}

respectively, were negatively correlated for white girls $(r=-.37$ and -.28$)$ but positively correlated for African-American girls [ $r=.10$ (non-significant; ns) and .29] and African-American boys $(r=.17$ and .15$)$. Coolness and concurrent academic reputation were positively correlated for white girls at both time points $(r=.37, .36)$ and for white boys in the fall $(r=.16)$. Coolness and concurrent academic reputation were negatively correlated in the fall for African-American boys $(r=-.16)$ and in the spring for African-American girls $(r=-.16)$. For all groups, disruptive behavior was negatively correlated with concurrent academic reputation (ranging from $r=-.51$ to -.83 ). All correlations are displayed in Table 3.

\section{Cool Status and Concurrent Academic Reputation}

Hierarchical regressions by group are displayed in Tables 4 and 5 . Hierarchical regressions were conducted to evaluate whether there was an interaction between coolness and disruptive behavior that was predictive of effort. Step 1 of the analysis included coolness, step 2 added disruptive behavior, and step 3 added the interaction of coolness and disruptive behavior. The standardized variables presented no significant multi- 
Table 3. Correlations among Variables by Group

\begin{tabular}{|c|c|c|c|c|c|c|}
\hline & T1 Cool & T2 Cool & T1 DB & T2 DB & T1 AR & T2 AR \\
\hline \multicolumn{7}{|l|}{ White } \\
\hline T1 Cool & - & $.702 * *$ & $-.297 * *$ & $-.294 * *$ & $.163 *$ & .118 \\
\hline T2 Cool & $.716^{* *}$ & - & $-.223 * *$ & -.102 & .072 & -.047 \\
\hline T1 DB & $-.368 * *$ & $-.354 * *$ & - & $.871 * *$ & $-.834 * *$ & $-.610 * *$ \\
\hline T2 DB & $-.397 * *$ & $-.282 *$ & $.774 * *$ & - & $-.750 * *$ & $-.745 * *$ \\
\hline T1 AR & $.369 * *$ & $.346^{* *}$ & $-.653 * *$ & $-.639 * *$ & - & $.732 * *$ \\
\hline T2 AR & $.358 * *$ & $.356 * *$ & $-.512 * *$ & $-.509 * *$ & $.716^{* *}$ & - \\
\hline \multicolumn{7}{|l|}{ Black } \\
\hline T1 Cool & - & $.656 * *$ & $.165 * *$ & .019 & $-.155^{*}$ & -.151 \\
\hline T2 Cool & $.607 * *$ & - & -.015 & $.149 *$ & .087 & -.149 \\
\hline T1 DB & .104 & $.163 * *$ & - & $.731 * *$ & $-.770 * *$ & $-.616^{* *}$ \\
\hline T2 DB & $.144^{*}$ & $.290 * *$ & $.708 * *$ & - & $-.550 * *$ & $-.779 * *$ \\
\hline T1 AR & .057 & -.102 & $-.664 * *$ & $-.622 * *$ & - & $.683 * *$ \\
\hline T2 AR & -.111 & $-.157 *$ & $-.536 * *$ & $-.657 * *$ & $.694 * *$ & - \\
\hline
\end{tabular}

Note: Boys score above diagonal, girls score below diagonal. $\mathrm{AR}=$ academic reputation; $\mathrm{DB}=$ disruptive behavior; $\mathrm{T} 1=$ fall $; \mathrm{T} 2=$ spring .

$* p<.05, * * p<.01$.

collinearity concerns (all Tolerance values $=.32-.99$ ). In the fall (see Table 3 ), being cool was positively related to academic reputation for African-American girls after controlling for disruptive behavior, but unrelated for African-American boys. There was a significant interaction of coolness and disruptive behavior for white students indicating that being seen as cool and disruptive was related to lower levels of peerreported effort (see Figure 1). More specifically, white boys who were more disruptive on average were reported by peers as having lower levels of effort; this effect was the strongest for those white boys who had high cool reputations. White girls who were less disruptive on average were reported by peers as having higher levels of effort; this effect was the strongest for those white girls who had high cool reputations. Alternatively, white girls who were more disruptive on average were reported by peers as having lower levels of effort; once again, this effect was the strongest for those white girls who had high cool reputations. Disruptive behavior was negatively related to academic reputation for all groups.

In the spring (see Table 4), being cool was positively related to academic reputation for white girls after controlling for disruptive behavior, but was negatively related to academic reputation for white boys. There was an interaction between being cool and disruptive behavior as they related to academic reputation for African-American boys (see Figure 2), indicating that being seen as cool and disruptive was related to lower levels of peer-reported effort. African-American boys who were less disruptive on average were reported by peers as having higher levels of effort; this effect was the strongest for those African-American boys who had high cool reputations. Alternatively, African-American boys who were more disruptive on average were reported by peers as having lower levels of effort; once again, this effect was the strongest for those who had high cool reputations. Similarly to concurrent relations in the fall, disruptive behavior in the spring was negatively related to concurrent academic reputation for all groups. 
394 Rhonda S. Jamison, Travis Wilson and Allison Ryan

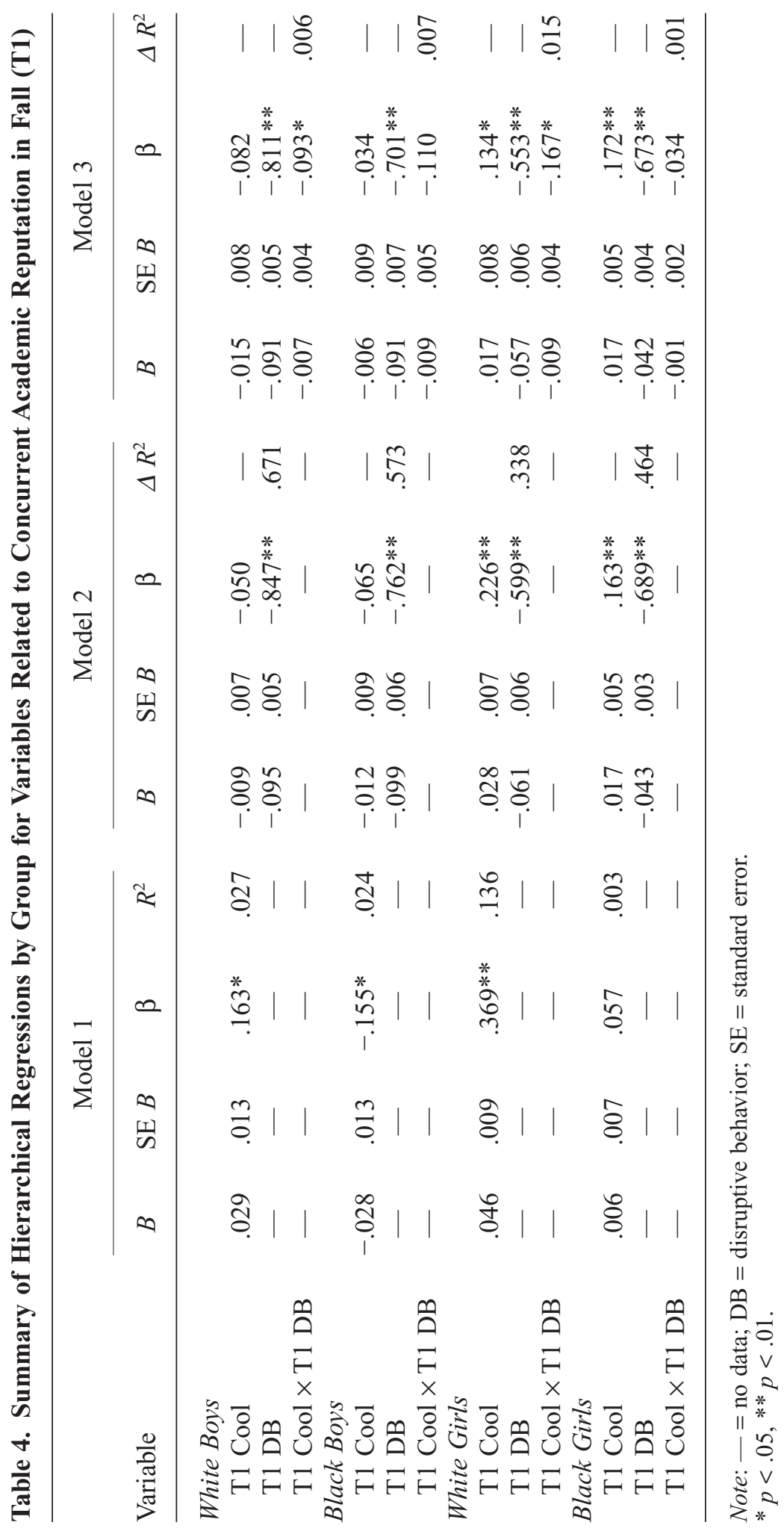




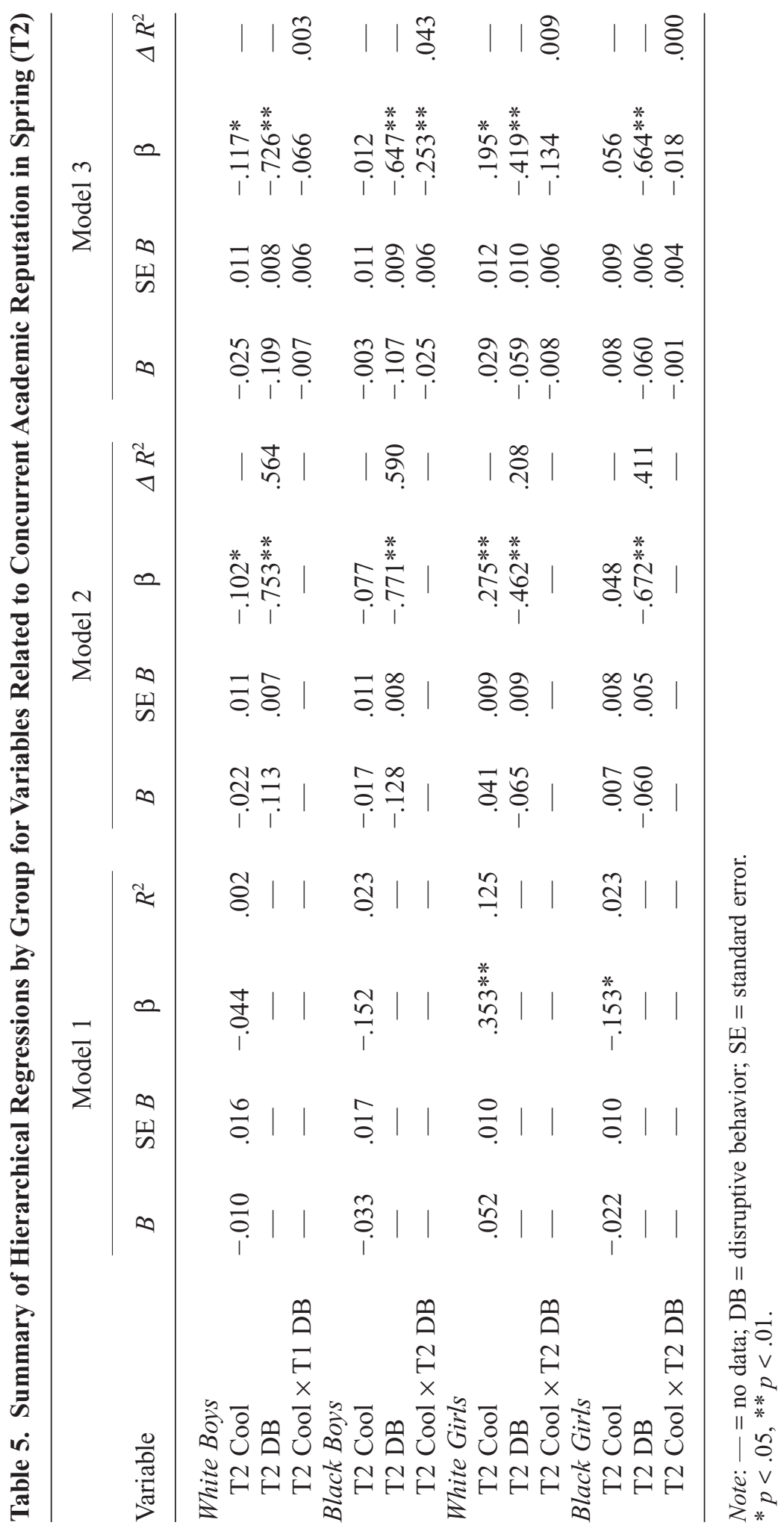


White Boys

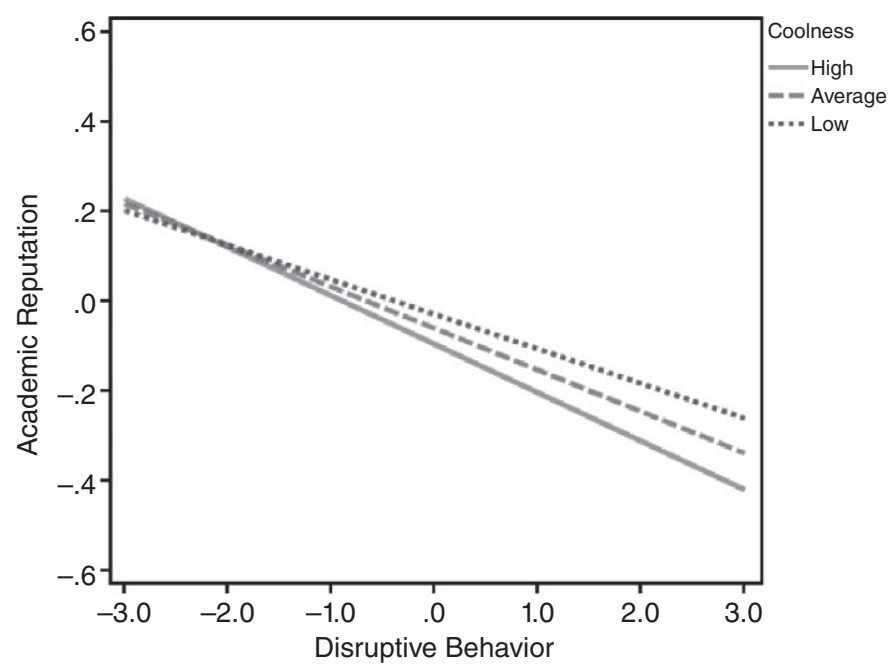

White Girls

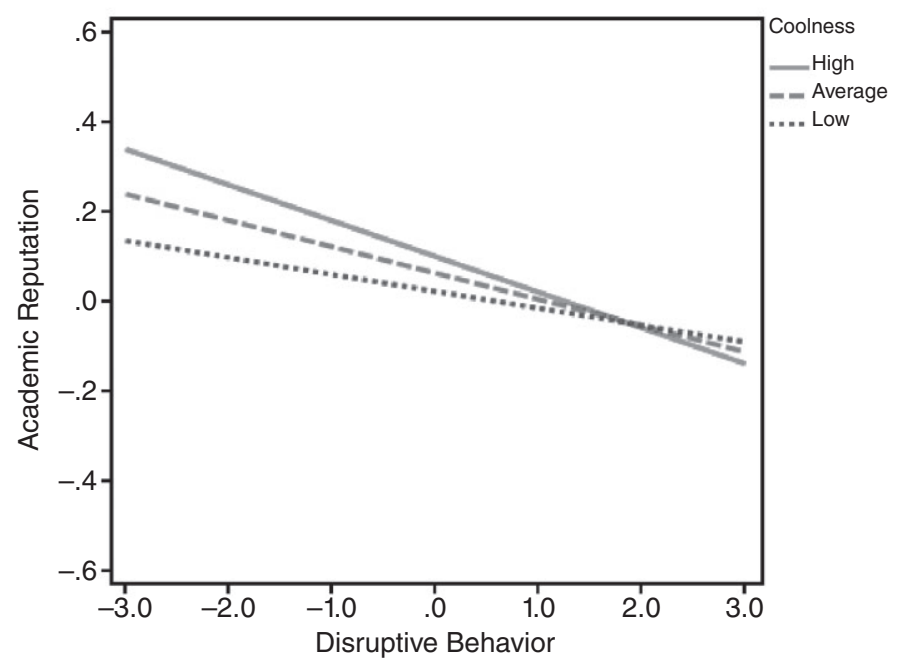

Figure 1. Interaction between Coolness and Disruptive Behavior at Time 1.

\section{Cool Status and Changes in Academic Reputation}

Hierarchical regressions by group are displayed in Table 6. Step 1 of the analysis included $\mathrm{T} 1$ academic reputation and $\mathrm{T} 1$ coolness, step 2 added $\mathrm{T} 1$ disruptive behavior, and step 3 added the interaction of $\mathrm{T} 1$ coolness and $\mathrm{T} 1$ disruptive behavior, all predicting T2 academic reputation. For African-American students, having a cool reputation in the fall of the school year was negatively associated with academic reputation in the spring of the year; that is, after controlling for initial academic 
African-American Boys

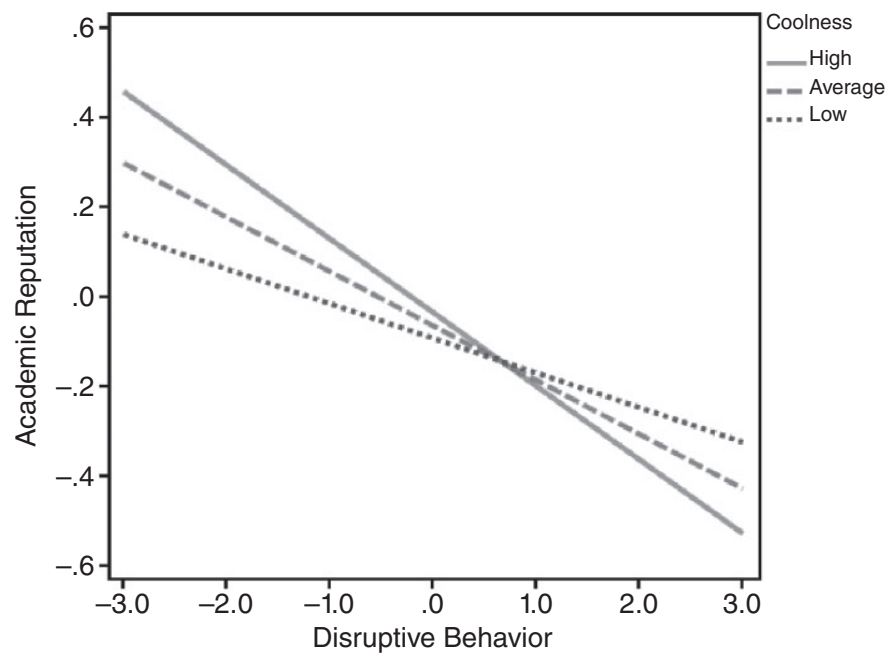

Figure 2. Interaction between Coolness and Disruptive Behavior at Time 2.

reputation and disruptive behavior, being cool at the beginning of the year was negatively associated with academic reputation at the end of the year. For white students, cool reputation and disruptive behavior were not significant predictors of academic reputation across the school year.

\section{Discussion}

Individual social adjustment and academic functioning in middle school are highly entwined within the peer ecology (Eccles \& Roeser, 2010). The present study explored the intersection of academic and social factors in early adolescence, when peers become increasingly influential, by examining the relationship between perceived coolness and academic reputation. Overall, results indicated that associations between coolness and academic reputation differed across subgroups, were contingent upon level of disruptive behavior, and changed over time from fall to spring of the academic year. Below, we first summarize and interpret key study findings in relation to other empirical studies and situated within an ecological systems framework (Bronfenbrenner, 1994; Lerner, 2006). We then discuss implications of study findings - and why they may differ by gender or by ethnicity-before addressing challenges for future research.

\section{Perceived Coolness and Disruptive Behavior}

Although links between coolness and academic reputation are the central focus of this study, associations between coolness and disruptive behavior first deserve consideration. Correlations differed between ethnic groups at both time points. AfricanAmerican students were reported by peers as being more disruptive than were European-American students, and African-Americans who were perceived as above 
398 Rhonda S. Jamison, Travis Wilson and Allison Ryan

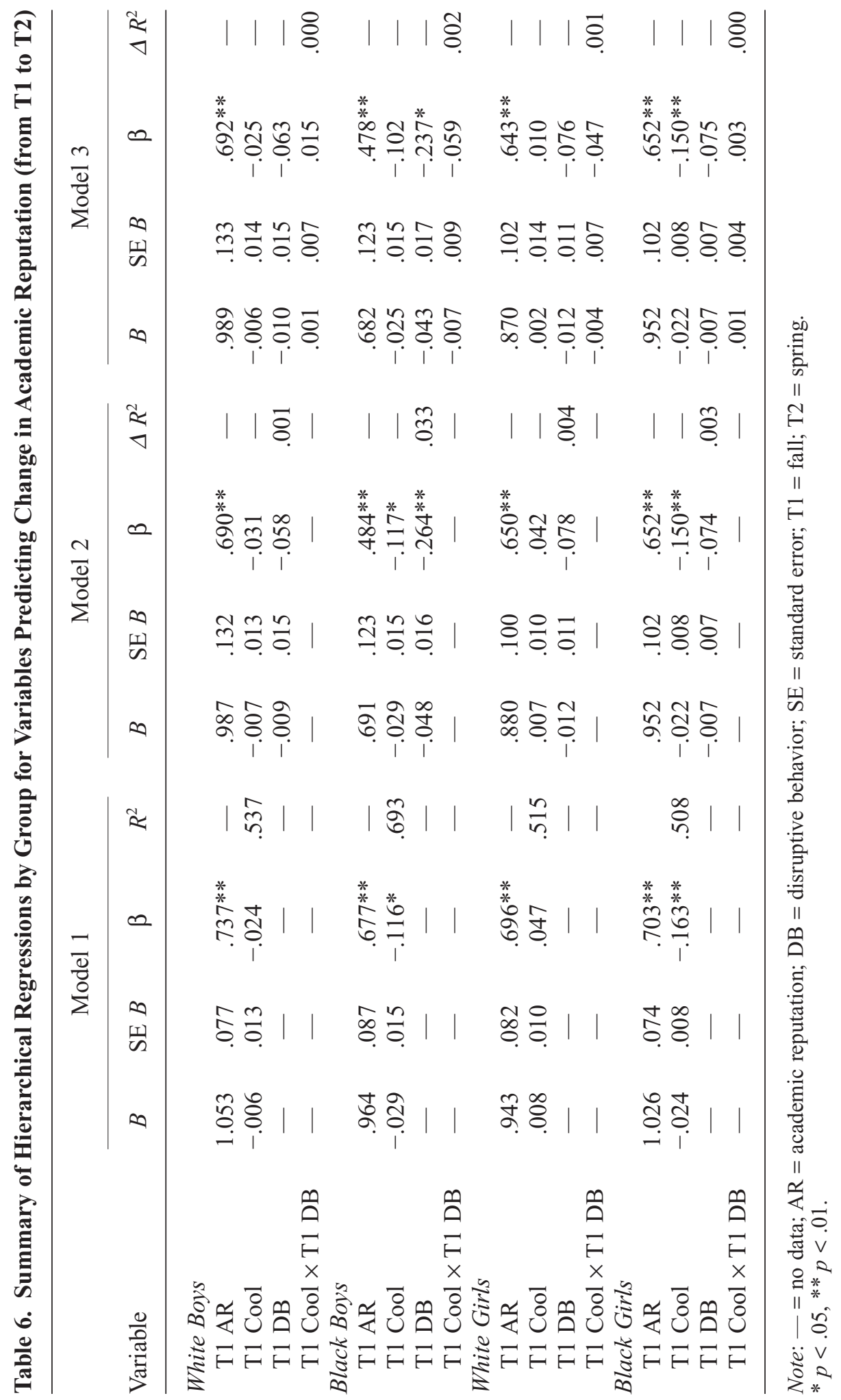


average in disruptive behavior were also viewed as more cool; for EuropeanAmericans, the reverse was true. These findings may in fact indicate that coolness and disruptive behavior are more strongly associated for young African-American than their European-American counterparts - at least in school contexts similar to those represented in our study; but given that these constructs were measured by peer ratings, stereotypes about African-Americans' aggressive and disruptive behavior may also have played a role (see Belmore, Nishina, \& Graham 2011).

That said, a positive link between perceived coolness and disruptive behavior may have mixed blessings for African-American students. In school environments where African-American students feel marginalized, overt displays of disruptive behavior may be a viable way to assert one's autonomy and self-worth to adults (Ferguson, 2001) or to mitigate peer rejection. On the other hand, to the extent that disruptive behavior may be reinforced in African-American children by virtue of being deemed cool by peers - albeit in tacit ways - and to the extent that disruptive behavior undermines academic engagement, these dynamics may represent additional challenges for African-American youth's academic success.

\section{Perceived Coolness and Academic Reputation}

A pervasive finding across subgroups and time was that a combination of coolness and disruptive behavior predicted the lowest levels of academic reputation. These findings are consistent with previous work by Troop-Gordon et al. (2011), who examined a predominantly white, rural sample of early adolescent children from fall of their fourth-grade year through spring of their fifth-grade year. Results indicated that children who had above-average levels of aggression and perceived popularity experienced trajectories of increasing school avoidance and declining academic performance over this two-year span; these negative trajectories were not evidenced for non-popular aggressive or popular non-aggressive students. Taken together, these two studies suggest that coolness may intensify the deleterious effects of classroom disruptive behavior on both actual and peer perceived academic engagement. Note that both studies addressed changes within person over time. That is, children who themselves were both disruptive and cool experienced diminished academic reputation or more school avoidance over time.

Also striking was how patterns of associations between coolness and academic reputation changed across the school year-and differentially so across subgroups. In the beginning of the school year, patterns differed by gender, not by ethnicity. For both white and African-American boys, hierarchical regressions evidenced a null association between coolness and academic reputation; for both white and African-American girls, this association was positive. Thus, in the fall, cool girls (but not cool boys) also tended to have positive academic reputations. These gender differences, parallel across ethnicity in the fall, were no longer parallel across ethnicity in the transition from fall to spring. For white girls, findings in the spring mirrored findings from the fall, as the coolness-academic reputation association was positive and nearly identical at both time points. However, for the three remaining groups-white boys and African-American boys and girls-conditions worsened over time, albeit in slightly dissimilar ways. For white boys, fall coolness did not predict significant declines in academic reputation over time; nonetheless, as a group, the coolness-academic reputation was negative by the end of the year. For African-American boys and girls, fall coolness did significantly predict 
declines in academic reputation from fall to spring, although the concurrent coolness-academic reputation association was not significantly negative for either group in the spring.

These findings may signal that the transition during the first year of middle school evidences a shift in the ways that gender and ethnicity interact within the peer culture - at least with respect to social behavior and peer reputation. At the beginning of seventh grade, in some respects, students are clearly distinguishable by gender (i.e., in coolness-academic reputation associations), perhaps still clinging in important ways to separate spheres of influence forged during early and middle childhood (Maccoby, 1996; Rose \& Smith, 2009). But in other respects, students were clearly distinguishable by ethnicity (in coolness-behavior associations); this is consistent with previous findings that students in middle school increasingly affiliate with same-ethnicity classmates (Graham et al., 2009) and, presumably, socialize with each other in ways that promote social adaptation in the face of developmental challenges unique to each ethnic group. To the extent that African-American and white girls were similar in the fall, this similarity weakened over time during the seventh-grade year, as the peer dynamics of African-American girls changed in ways more similar to AfricanAmerican (and white) boys than to white girls. These dynamics may have broader implications for how gender roles and ethnic identities are codified in the peer system during early adolescence.

\section{Future Directions and Conclusion}

One avenue for future research concerns whether cool status - or other markers of prestige-have enduring, manifold repercussions for adolescents. Compared with rejected status, which is consistently linked to negative developmental trajectories in academic functioning and psychological adjustment, less is known about the long-term developmental trajectories of adolescents perceived as cool or popular (Prinstein, Rancourt, Guerry, \& Browne, 2009). The present research, as well as prior studies of younger students (e.g., Rodkin et al., 2000; Troop-Gordon et al., 2011), suggest that the conjoining of prestige and deviant behavior - not necessarily prestige alone - may predict maladaptive patterns in the long term, although this remains an open question. There may be unique implications for ethnic minorities, who typically have fewer economic and institutional safety nets to bolster resilience against developmental challenges. A consistently reported phenomenon in the developmental literature is that despite exposure to discrimination and institutionalized racism, ethnic minority children's self-esteem often outpaces ethnic majority youth's self-esteem throughout adolescence (Gray-Little \& Hafdahl, 2000; Verkuyten, 2008). Being a part of an ethnic group perceived as cool or popular may contribute to this trend, so having elevated status or visibility may in fact have trade-offs for ethnic minority adolescents in ways not experienced by white adolescents; again, the long-term implications of these dynamics are unknown.

More generally, the field will benefit from continued investigation of the ways students' social development relates to academic achievement, motivation, and engagement during middle school, especially by examining additional constructs not included in this study. For example, future studies might examine how relationally aggressive behavior is related to coolness and academic reputation. Another promising direction would be to consider how students internalize implicit messages conveyed via social status systems in ways that bear upon sense of academic efficacy or explicit 
valuing of school. In addition, research involving other ethnic groups is needed. Because our sample comprised African-American and white students, we cannot speak to the relationship between being cool and academic reputation for other ethnic groups.

This study provides insight into the intersection of academic and social development of students. This is the first study to examine how perceived coolness is related to academic reputation and how status relates to change in academic reputation over time. Our findings illustrate that students' academic and social development are intertwined in such a way that exploration of one without considering the other may lead researchers astray. School and classroom environments, along with the social interactions that take place in those environments, are integral to understanding students' varied academic outcomes.

\section{References}

Archer, J. (2004). Sex differences in aggression in real-world settings: A meta-analytic review. Review of General Psychology, 8, 291-322. http://dx.doi.org/10.1037/1089-2680.8.4.291

Asher, S. R., \& Coie, J. D. (Eds.). (1990). Peer rejection in childhood. New York: Cambridge University Press.

Barry, C. M., \& Wentzel, K. R. (2006). Friend influence on prosocial behavior: The role of motivational factors and friendship characteristics. Developmental Psychology, 42, 153-163. http://dx.doi.org/10.1037/0012-1649.42.1.153

Baumeister, R. F., \& Sommer, K. L. (1997). What do men want? Gender differences and two spheres of belongingness: Comment on Cross and Madson (1997). Psychological Bulletin, 122, 38-44. http://dx.doi.org/10.1037/0033-2909.122.1.38

Bellmore, A., Nishina, A., \& Graham, S. (2011). Peer popularity in the context of ethnicity. In A. H. N. Cillessen, D. Schwartz, \& L. Mayeux (Eds.), Popularity in the peer system (pp. 193-218). New York: Guilford.

Bellmore, A., Villarreal, V. M., \& Ho, A. Y. (2011). Staying cool across the first year of middle school. Journal of Youth and Adolescence, 40, 776-785. http://dx.doi.org/10.1007/s10964010-9590-x

Berndt, T. J., \& Savin-Williams, R. C. (1993). Peer relations and friendships. Oxford: John Wiley \& Sons.

Blatchford, P., Baines, E., \& Pellegrini, A. (2003). The social context of school playground games: Sex and ethnic differences, and changes over time after entry to junior school. The British Journal of Developmental Psychology, 21, 481-505. http://dx.doi.org/10.1348/ 026151003322535183

Bronfenbrenner, U. (1994). Ecological models of human development. In T. N. Postlethwaite, \& T. Husen (Eds.), International encyclopedia of education (Vol. 3, 2nd ed., pp. 1643-1647). Oxford: Elsevier. Reprinted in Gauvain, M. \& Cole, M. (Eds.), Readings on the development of children, $2^{\text {nd }}$ Ed. (1993, pp. 37-43). NY: Freeman.

Bukowski, W. M., Sippola, L. K., \& Newcomb, A. F. (2000). Variations in patterns of attraction of same- and other-sex peers during early adolescence. Developmental Psychology, 36, 147-154. doi: 10.1037/0012-1649.36.2.147

Carter, P. L. (2006). Straddling boundaries: Identity, culture, and school. Sociology of Education, 79, 304-328.

Cillessen, A. H. N., \& Mayeux, L. (2007). Expectations and perceptions at school transitions: The role of peer status and aggression. Journal of School Psychology, 45, 567-586. doi: 10.1016/j.jsp.2007.05.004

Cillessen, A. H. N., \& Rose, A. J. (2005). Understanding popularity in the peer system. Current Directions in Psychological Science, 14, 102-105. doi: 10.1111/j.0963-7214.2005.00343.x

Cillessen, A. H. N., \& van den Berg, Y. H. M. (2012). Popularity and school adjustment. In A. M. Ryan, \& G. W. Ladd (Eds.), Peer relationships and adjustment at school (pp. 135-164). Charlotte, NC: Information Age Publishing.

Closson, L. M. (2009). Status and gender differences in early adolescents' descriptions of popularity. Social Development, 18, 412-426. doi: 10.1111/j.1467-9507.2008.00459.x 
Downey, D. B., \& Ainsworth-Darnell, J. (2002). The search for oppositional culture among black students. American Sociological Review, 67, 156-164. http://dx.doi.org/10.2307/ 3088939

Eccles, J. S. (2004). Schools, academic motivation, and stage-environment fit. Hoboken, NJ: John Wiley \& Sons Inc.

Eccles, J. S., \& Roeser, R. (2010). An ecological view of schools and development. In J. Meece, \& J. Eccles (Eds.), Handbook of research on schools, schooling, and human development (ch. 2) (pp. 6-21). New York: Routledge.

Eccles, J. S., Midgley, C., Wigfield, A., Buchanan, C. M., Reuman, D., Flanagan, C., \& Mac Iver, D. (1993). Development during adolescence: The impact of stage-environment fit on young adolescents' experiences in schools and in families. The American Psychologist, 48, 90-101. doi: 10.1037/0003-066X.48.2.90. Special Issue: Adolescence

Ferguson, A. A. (2001). Public schools in the making of black masculinity. Ann Arbor, MI: The University of Michigan Press.

Fisher, C. B., Wallace, S. A., \& Fenton, R. E. (2000). Discrimination distress during adolescence. Journal of Youth and Adolescence, 29, 679-695.

Graham, S., Taylor, A. Z., \& Hudley, C. (1998). Exploring achievement values among ethnic minority early adolescents. Journal of Educational Psychology, 90, 606-620. http:// dx.doi.org/10.1037/0022-0663.90.4.606

Graham, S., Taylor, A. Z., \& Ho, A. Y. (2009). Race and ethnicity in peer relations research. In K. H. Rubin, W. M. Bukowski, \& B. Laursen (Eds.), Handbook of peer interactions, relationships, and groups (pp. 394-413). New York: The Guilford Press.

Gray-Little, B., \& Hafdahl, A. R. (2000). Factors influencing racial comparisons of self-esteem: A quantitative review. Psychological Bulletin, 126, 26-54. doi: 10.1177/0095798406295096

Hoff, K. E., Reese-Weber, M., Schneider, W. J., \& Stagg, J. W. (2009). The association between high status positions and aggressive behavior in early adolescence. Journal of School Psychology, 47, 395-426. doi: 10.1016/j.jsp.2009.07.003

Jordan, W. J., \& Cooper, R. (2003). High school reform and black male students: Limits and possibilities of policy and practice. Urban Education, 38, 196-216. http://dx.doi.org/10.1177/ 0042085902250485

Juvonen, J., \& Murdock, T. B. (1995). Grade-level differences in the social value of effort: Implications for self-presentation tactics of early adolescents. Child Development, 66, 16941705. doi: 10.1111/1467-8624.ep9601152096

Kenney-Benson, G., Pomerantz, E. M., Ryan, A. M., \& Patrick, H. (2006). Sex differences in math performance: The role of children's approach to schoolwork. Developmental Psychology, 42, 11-26. http://dx.doi.org/10.1037/0012-1649.42.1.11

Kiefer, S. M., \& Ryan, A. (2011). Students' perceptions of characteristics associated with social success: Changes during early adolescence. Journal of Applied Developmental Psychology, 32, 218-226. doi: 10.1016/j.appdev.2011.05.002

LaFontana, K. M., \& Cillessen, A. H. N. (2002). Children's perceptions of popular and unpopular peers: A multimethod assessment. Developmental Psychology, 38, 635-647. doi: 10.1037/0012-1649.38.5.635

LaFontana, K. M., \& Cillessen, A. H. N. (2010). Developmental changes in the priority of perceived status in childhood and adolescence. Social Development, 19, 130-147. doi: 10.1111/j.1467-9507.2008.00522.x

Larson, R. W., Wilson, S., Brown, B. B., Furstenberg, J., Frank, F., \& Verma, S. (2002). Changes in adolescents' interpersonal experiences: Are they being prepared for adult relationships in the twenty-first century? Journal of Research on Adolescence, 12, 31-68.

Lerner, R. M. (2006). Developmental science, developmental systems, and contemporary theories of human development. In R. A. Lerner (Ed.), Handbook of child psychology (Vol. 1, 6th ed., pp. 1-17), Theoretical models of human development. Hoboken, NJ: Wiley.

Maccoby, E. E. (1996). Peer conflict and intrafamily conflict: Are there conceptual bridges? Merrill-Palmer Quarterly, 42, 165-176.

Mathur, R., \& Berndt, T. J. (2006). Relations of friends' activities to friendship quality. The Journal of Early Adolescence, 26, 365-388. http://dx.doi.org/10.1177/0272431606288553

Mayeux, L., Sandstrom, M. J., \& Cillessen, A. H. N. (2008). Is being popular a risky proposition? Journal of Research on Adolescence, 18, 49-74. doi: 10.1111/j.15327795.2008.00550.x 
Meece, J. L., Anderman, E. M., \& Anderman, L. H. (2006). Classroom goal structure, student motivation, and academic achievement. Annual Review of Psychology, 57, 487-503.

Mickelson, R. A. (1990). The attitude-achievement paradox among black adolescents. Sociology of Education, 63, 44-61.

Moffitt, T. E. (1993). Adolescence-limited and life-course-persistent antisocial behavior: A developmental taxonomy. Psychological Review, 100, 674-701. doi: 10.1037/0033295X.100.4.674

O'Connor, C. (1999). Race, class, and gender in America: Narratives of opportunity among low-income African American youths. Sociology of Education, 72, 137-157.

Parker, J. G., \& Asher, S. R. (1987). Peer relations and later personal adjustment: Are lowaccepted children at risk? Psychological Bulletin, 102, 357-389. doi: 10.1037/00332909.102.3.357

Prinstein, M. J., Rancourt, D., Guerry, J. D., \& Browne, C. B. (2009). Peer reputations and psychological adjustment. In K. H. Rubin, W. M. Bukowski, \& B. Laursen (Eds.), Handbook of peer interactions, relationships, and groups (pp. 548-567). New York: The Guilford Press.

Rodkin, P. C., Farmer, T. W., Pearl, R., \& Van Acker, R. (2000). Heterogeneity of popular boys: Antisocial and prosocial configurations. Developmental Psychology, 36, 14-24. doi: 10.1037/ 0012-1649.36.1.14

Rodkin, P. C., Farmer, T. W., Pearl, R., \& Van Acker, R. (2006). They're cool: Social status and peer group supports for aggressive boys and girls. Social Development, 15, 175-204. doi: 10.1111/j.1467-9507.2006.00336.x

Rose, A. J., \& Rudolph, K. D. (2006). A review of sex differences in peer relationship processes: Potential trade-offs for the emotional and behavioral development of girls and boys. Psychological Bulletin, 132, 98-131. http://dx.doi.org/10.1037/0033-2909.132.1.98

Rose, A. J., \& Smith, R. L. (2009). Sex differences in peer relationships. In K. H. Rubin, W. M. Bukowski, \& B. Laursen (Eds.), Handbook of peer interactions, relationships, and groups (pp. 379-393). New York: Guilford.

Rose, A. J., Glick, G. C., \& Smith, R. L. (2011). Popularity and gender: The two cultures of boys and girls. In A. H. N. Cillessen, D. Schwartz, \& L. Mayeux (Eds.), Popularity in the peer system (pp. 103-122). New York: Guilford.

Sandstrom, M. J., \& Cillessen, A. H. N. (2006). Likeable versus popular: Distinct implications for adolescent adjustment. International Journal of Behavioral Development, 30, 305-314. doi: 10.1177/0165025406072789

Schwartz, D., Gorman, A. H., Nakamoto, J., \& McKay, T. (2006). Popularity, social acceptance, and aggression in adolescent peer groups: Links with academic performance and school attendance. Developmental Psychology, 42, 1116-1127. http://dx.doi.org/10.1037/00121649.42.6.1116

Taylor, A. Z., \& Graham, S. (2007). An examination of the relationship between achievement values and perceptions of barriers among low-SES African American and Latino students. Journal of Educational Psychology, 99, 52-64. http://dx.doi.org/10.1037/0022-0663.99.1.52

Taylor, R. D., Casten, R., Flickinger, S. M., Roberts, D., \& Fulmore, C. D. (1994). Explaining the school performance of African-American adolescents. Journal of Research on Adolescence, 4, 21-44.

Troop-Gordon, W., Visconti, K. J., \& Kuntz, K. J. (2011). Perceived popularity during early adolescence: Links to declining school adjustment among aggressive youth. The Journal of Early Adolescence, 31, 125-151. doi: 10.1177/0272431610384488

Verkuyten, M. (2008). Perceived discrimination, ethnic minority identity, and self-esteeem. In S. M. Quintana, \& C. McKown (Eds.), Handbook of race, racism, and the developing child (pp. 339-365). Hoboken, NJ: Wiley.

Wentzel, K. R., \& Asher, S. R. (1995). The academic lives of neglected, rejected, popular, and controversial children. Child Development, 66, 754-763. doi: 10.2307/1131948

Wigfield, A., Eccles, J. S., Schiefele, U., Roeser, R. W., \& Davis-Kean, P. (2006). Development of achievement motivation. Hoboken, NJ: John Wiley \& Sons.

Wong, C. A., Eccles, J. S., \& Sameroff, A. (2003). The influence of ethnic discrimination and ethnic identification on African American adolescents' school and socioemotional adjustment. Journal of Personality, 71, 1197-1232. http://dx.doi.org/10.1111/1467-6494.7106012 